\title{
Correlates of knowledge on birth defects and associated factors among antenatal mothers in Galle, Sri Lanka: a cross- sectional analytical study
}

\author{
Janithra De Silva ${ }^{1 *}$ (D) Sujeewa Amarasena ${ }^{2}$, Kapila Jayaratne ${ }^{3}$ and Bilesha Perera ${ }^{1}$
}

\begin{abstract}
Background: Birth defects (BD) are considered a leading cause of childhood morbidity and mortality. Personal, cultural, and health care system barriers may increase the incidence of BD in low and middle income countries. In this study we assessed the knowledge of antenatal mothers on BD, associated factors, and prevention and management.

Methods: Three hundred and fifty (350) antenatal mothers were surveyed using a pretested, self-administered questionnaire. The knowledge on BD was evaluated under 3 categories; knowledge on BD, knowledge on associated factors, and knowledge on prevention and management. The total scores were calculated for each category and converted into percentages. A higher percentage score indicates a high level of knowledge. Descriptive statistics and regression models were used for data analysis. Level of significance was considered as $p<0.05$.

Results: Mean age of the participants was 28.7 years $(S D=5.2)$. The age range was $17-44$ years. Most of the participants (79\%) had studied up to secondary or tertiary education. The average scores of knowledge on $\mathrm{BD}$, associated factors, and prevention and management of BD were $57.6 \%(95 \% \mathrm{Cl}=52.3-62.9 \%)$, 55.1\% (95\% $\mathrm{Cl}=49.8-60.4 \%)$ and $58.8 \%(95 \% \mathrm{Cl}=53.5-64.1 \%)$ respectively. The average score on the overall total knowledge was $56.4 \%(95 \% \mathrm{Cl}=51.1-61.7 \%)$. Mother's level of education, monthly income of the family and number of clinic visits made by the mother were found to be positively associated with the overall knowledge. About $62 \%$ of the participants had taken folic acid (FA) preconceptionally, a major preventive factor of BD associated with the nervous system. Folic acid intake was positively associated with age and educational level, but negatively associated with parity. Media (36.9\%) and Public Health Midwives (PHMs) (20\%) were found to be the major sources of knowledge on $\mathrm{BD}$, associated factors and prevention in this target group.
\end{abstract}

Conclusions: The average overall knowledge on BD in this group of antenatal mothers was moderate. Thus, there is a need to improve the knowledge in eligible women to reduce the occurrence of $\mathrm{BD}$, ideally before they become pregnant. Media and PHMs were seem to be the effective and possible resources that can be used to educate the community on BD, associated factors and prevention of BD in Sri Lanka.

Keywords: Birth defects, Associated factors, Prevention, Knowledge, Folic acid, Antenatal mothers, Sri Lanka

\footnotetext{
* Correspondence: janithradesilva@gmail.com

${ }^{1}$ Department of Community Medicine, Faculty of Medicine, University of

Ruhuna, Galle, Sri Lanka

Full list of author information is available at the end of the article
}

(c) The Author(s). 2019 Open Access This article is distributed under the terms of the Creative Commons Attribution 4.0 International License (http://creativecommons.org/licenses/by/4.0/), which permits unrestricted use, distribution, and reproduction in any medium, provided you give appropriate credit to the original author(s) and the source, provide a link to the Creative Commons license, and indicate if changes were made. The Creative Commons Public Domain Dedication waiver (http://creativecommons.org/publicdomain/zero/1.0/) applies to the data made available in this article, unless otherwise stated. 


\section{Background}

Birth defects (BD) are a diverse group of abnormalities of prenatal origin that occur in relation to the structure or function of the individuals $[1,2]$. They are well known as a significant and a serious public health problem because of the high morbidity and mortality associated with them [2-4]. Apart from the adverse outcomes in the affected individual, BD impose a huge burden on social, psychological, health aspects and economy of the caregivers and the family. Birth defects are known as a global health problem causing deaths of 303,000 newborns within the first 4 weeks of life each year worldwide [5]. However, the occurrence and the impact of BD are found to be higher in low and middle income countries. More than $94 \%$ of serious BD occur in these countries and nearly $95 \%$ of the children with severe BD would die eventually $[1,5]$. It is said that these differences among developed and developing countries could be partly due to the differences in socio-economic conditions of the individuals and countries, availability of health care facilities and cultural aspects [1]. In addition, lack of knowledge and education of the mothers on $\mathrm{BD}$, the risk factors of $\mathrm{BD}$ and the prevention of $\mathrm{BD}$ have been identified as major factors which hinder the prevention of BD $[1,2]$. Because of the higher morbidity and mortality associated with $\mathrm{BD}$, many countries were not able to achieve the United Nations Millennium Development Goal (MDG) 4 set as to reduce the under-five mortality rate by two-thirds between 1990 and 2015 even though the mortality due to most other causes showed a decline $[1,2]$.

Sri Lanka, although being a country doing well in maternal and child health, has borne the burden of BD. A study conducted in Sri Lanka in 2014 has found a $4.3 \%$ prevalence of birth defects among newborns [6]. Added to that $\mathrm{BD}$ have become a leading cause of mortality among children under 5 years in Sri Lanka and the proportional mortality due to $\mathrm{BD}$ has increased during the recent years [1, 7-9]. In $2015 \mathrm{BD}$ contributed $46.5 \%$ of infant deaths and $36.8 \%$ of 1 to 5 year child deaths [8] and in 2016, the contribution for infant and 1-5 year child deaths was 54.5 and $34.5 \%$ respectively [9]. Therefore, prevention and proper management of $\mathrm{BD}$ has become a priority issue in child health in Sri Lanka. With this background Sri Lanka initiated birth defects surveillance in 2014 and the pilot program was conducted in Galle district.

Though, BD carry a high morbidity and mortality they are considered to be preventable to a large extent [2]. Several interventions such as preconceptional folic acid (FA) supplementation, iodization of food items like salt, immunization with rubella vaccine, screening and treatment of syphilis during pregnancy, identification and management of preexisting health conditions, improvement of nutritional status of the mothers have been each identified as cost-effective preventive strategies of $\mathrm{BD}[1,2]$. Adding up to these interventions, health education of the mothers and the public has also been identified as a major method in the prevention of BD [1].

Knowledge regarding $\mathrm{BD}$ and the management of $\mathrm{BD}$ is not only important for the prevention of $\mathrm{BD}$, but for the betterment of the affected individuals as well. The higher the knowledge the parents or the care givers would be having, the higher the chances to reduce the morbidity and mortality associated with BD. Further, the affected children can be saved from adverse social outcomes like social stigmatization and from the extreme consequences like infanticide if mothers are aware on the management options of $\mathrm{BD}$ [10]. Higher knowledge on $\mathrm{BD}$, associated factors, prevention and management would invariably minimize the adverse social, psychological, health and economic impacts to the family and eventually the negative impacts to the country.

This study was planned to assess the knowledge of the antenatal mothers on $\mathrm{BD}$, associated factors and prevention and management, and to identify the correlates of such knowledge. We also assessed the preconceptional FA intake and the awareness on the importance of preconceptional FA among the antenatal mothers in Galle, Sri Lanka.

\section{Methods \\ Participants}

This study was conducted in Galle district, one of the three districts of Southern Sri Lanka. Health care services are delivered to the community by two teaching hospitals and three base hospitals in the district. Field health care services are delivered by 20 Medical Officer of Health (MOH) units. In 2016, 20,796 pregnancies were estimated and 18,905 live births were reported in Galle district [9].

Antenatal mothers attending in six antenatal clinic centers in a health unit area in Galle district in the Southern province of Sri Lanka were recruited for the study. The mothers who were able to read and understand Sinhala language and who gave consent to participate in the study were recruited using a systematic sampling method.

\section{Data collection instrument}

A self-administered questionnaire was used to collect data. It was pretested using a sample of antenatal mothers attending antenatal clinics in another health unit in Galle district. Please see the attached Additional file 1 for more details.

In the development of the questionnaire for the study, the questionnaire developed by Bello et al., (2013) was used as a reference [3]. Additional questions were added to address the aims of the study. Face validity of the 
questionnaire was evaluated by two consultant community physicians and two consultant paediatricians.

The questionnaire consisted of two parts; part A to identify the socio-demographic characteristics of the respondents and part $\mathrm{B}$ to assess the knowledge of the mothers. In part $A$ of the questionnaire sociodemographic variables including age, highest educational qualification, monthly income, parity, having children with $\mathrm{BD}$, and the number of clinics attended were gathered. Participants were questioned whether they have heard or learnt about $\mathrm{BD}$, and if so from whom or from where they received that information. An added question was included to state whether they had taken preconceptional FA and if so, to state the reason for them to take preconceptional FA supplementation.

In part B of the questionnaire mothers' knowledge on $\mathrm{BD}$ was assessed under 3 sections namely, knowledge on $\mathrm{BD}$, knowledge on the associated factors of $\mathrm{BD}$ and knowledge on prevention and management of $\mathrm{BD}$ using 10, 21 and 7 statements respectively. In all 3 sections mothers were asked to mark their responses stating whether the given statement is true, false or do not know. A correct response was given $\mathrm{a}+1$ and an incorrect response or a do not know response was given 0 marks. The total marks were calculated for each category and converted into percentages.

\section{Procedure}

Ethical approval for the study was obtained from the Ethics Review Committee of the Faculty of Medicine, University of Ruhuna, Galle, Sri Lanka. Informed written consent was obtained from the participants after an initial information session. Non - response rate was $2 \%$. The participants who agreed to participate in the study $(n=350)$ were given instructions about the study, the aims and the risks and benefits of the study. They were asked to mark their responses for the statements in the given spaces.

\section{Data analysis}

Data were coded and entered into a database created using the Statistical Package of Social Science (SPSS) version 20.0. Descriptive statistics were used to describe the socio-demographic characteristics and the results were presented as means, frequencies and percentages. The total scores of each category of knowledge were calculated and converted into percentages. Data were analyzed using the SPSS 20 version and $t$ test was used to determine the differences between groups. The level of significance was considered as $p<0.05$. Linear regression models were used to identify the factors associated with the knowledge on BD. To identify the factors associated with the preconceptional FA intake and the knowledge on the importance of preconceptional FA, univariate and multivariate logistic regression analysis were conducted.

\section{Results}

Socio-demographic characteristics of the participants

A sample of 350 antenatal mothers residing in selected Health Unit was included in the analysis. The majority $313(89.4 \%)$ of the participants were Sinhalese while $35(10 \%)$ were Muslims and 2(0.6\%) were Tamils. The mean age of the participants was $28.7 \quad(S D=5.2)$ years and the age range was 17 to 44 years. The majority $(n=275,78.6 \%)$ have studied above the secondary school; studying beyond the General Certificate of Education of Ordinary Level exam conducted at grade 11 in Sri Lanka and 51(14.6\%) out of them have had higher education. Eighty two participants (23.4\%) were employed. The monthly income of the majority of the participants $(n=166$, 47.4\%) was between 25,000-49,000 Sri Lankan rupees (140-275 US dollars). There were 14(7.1\%) multiparous mothers who already had a child with BD. Of the total, 154(44\%) were primiparous mothers. Table 1 shows the socio-demographic characteristics of the participants.

Table 1 Socio-demographic characteristics of the participants $(n=350)$

\begin{tabular}{|c|c|c|}
\hline Demographic characteristic & $n$ & $\%$ \\
\hline \multicolumn{3}{|l|}{ Age (years) } \\
\hline$<25$ & 83 & 23.7 \\
\hline $25-34$ & 220 & 62.9 \\
\hline$\geq 35$ & 47 & 13.4 \\
\hline \multicolumn{3}{|l|}{ Educational level } \\
\hline Up to secondary school & 75 & 21.4 \\
\hline Above secondary school & 224 & 64.0 \\
\hline Higher education & 51 & 14.6 \\
\hline \multicolumn{3}{|c|}{ Monthly income (Sri Lankan Rupees) } \\
\hline$<25,000$ & 112 & 32.0 \\
\hline $25,000-49,000$ & 166 & 47.4 \\
\hline$\geq 50,000$ & 72 & 20.6 \\
\hline \multicolumn{3}{|l|}{ Parity } \\
\hline Primiparous & 154 & 44.0 \\
\hline Multiparous & 196 & 56.0 \\
\hline \multicolumn{3}{|l|}{ Kids with BD } \\
\hline Yes & 14 & 4.0 \\
\hline No & 336 & 96.0 \\
\hline \multicolumn{3}{|l|}{ Number of antenatal visits } \\
\hline$\leq 5$ & 169 & 48.3 \\
\hline $6-15$ & 163 & 46.6 \\
\hline$\geq 16$ & 18 & 5.1 \\
\hline
\end{tabular}




\section{The knowledge on BD and the correlates of knowledge on BD}

The average scores of knowledge on $\mathrm{BD}$, associated factors and prevention and management were $57.6 \%$ (95\% $\mathrm{CI}=52.3-62.9 \%), \quad 55.1 \% \quad(95 \% \quad \mathrm{CI}=49.8-60.4 \%) \quad$ and $58.8 \%(95 \% \mathrm{CI}=53.5-64.1 \%)$ respectively. The average score on overall knowledge was $56.4 \%$ (95\% CI $=51.1-$ $61.7 \%)$.

Linear regression analysis results of the predictors of overall knowledge on $\mathrm{BD}$ are shown in the Table 2. Mothers' with higher educational attainment $(p<0.001)$, higher monthly income $(p=0.015)$ and higher number of antenatal clinic visits $(\mathrm{p}<0.001)$ are found to have a higher overall knowledge. Age $(p=0.480)$ and parity $(p=0.348)$ of the mother and having children with $\mathrm{BD}(p=0.878)$ were not associated with overall knowledge on BD.

\section{Sources of information on BD among antenatal mothers} In this sample the majority of mothers $(n=265,75.7 \%)$ had heard or learnt about BD. Those who had heard about $\mathrm{BD}$ and the associated factors had a higher average overall knowledge compared to those who had not (59.6\% vs $46.4 \%, p<0.001)$. Table 3 shows the sources of knowledge on $\mathrm{BD}$, associated factors, prevention and management.

The major sources of information on $\mathrm{BD}$, associated factors, prevention and management for the antenatal mothers in this target population were Public Health Midwives (PHMs) (20.0\%) and the printed (18.5\%) and electronic media (18.4\%).

\section{Pre-conceptional folic acid consumption and awareness}

Almost two thirds of mothers in the sample $(n=218$, 62.3\%) had taken preconceptional folic acid (FA). Among them the majority $(n=146,70.0 \%)$ were in the age group 25 to 34 years. The majority $(n=185$, $84.9 \%)$ had studied above secondary school level and 44 (23.8\%) among them had higher education. Out of the total who had FA preconceptionally, 110 (50.4\%) were primiparous mothers, which is a $71.4 \%$ of the total number of primiparous mothers in the sample.

Table 2 Linear regression analysis of the effect of sociodemographic characteristics on overall knowledge on BD

\begin{tabular}{lllll}
\hline Variable & $\mathrm{B}$ & $\mathrm{SE}$ & $\mathrm{t}$ & $\mathrm{p}$ \\
\hline Constant & 0.125 & 0.128 & 0.973 & 0.331 \\
Maternal age & 0.002 & 0.002 & 0.882 & 0.378 \\
Educational level of the mother & 0.118 & 0.019 & 6.194 & 0.000 \\
Monthly income & 0.003 & 0.000 & 2.455 & 0.015 \\
Parity & 0.018 & 0.014 & 1.286 & 0.199 \\
Having kids with BD & 0.010 & 0.054 & 0.184 & 0.854 \\
Total number of clinic visits attended & 0.009 & 0.002 & 3.953 & 0.000 \\
\hline
\end{tabular}

Table 3 The sources of information on BD $(n=265)$

\begin{tabular}{lll}
\hline Source & $\mathrm{n}$ & $\%$ \\
\hline Consultant obstetrician & 52 & 6.4 \\
Family doctor & 29 & 3.6 \\
Medical Officer of Health (MOH) & 33 & 4.1 \\
Other doctor & 16 & 1.9 \\
Public Health Midwife (PHM) & 162 & 20.0 \\
Other health care personnel & 21 & 2.6 \\
Printed media & 150 & 18.5 \\
Electronic media & 149 & 18.4 \\
Internet & 44 & 5.4 \\
Parent/relative of a child with BD & 14 & 1.7 \\
School/Higher education institution & 63 & 7.8 \\
Relatives/friends & 77 & 9.5 \\
\hline
\end{tabular}

Among the multiparous mothers $(n=196)$ in the study sample only $55.1 \%$ have taken preconceptional FA.

Results of the univariate and multivariate regression analysis used to identify the factors associated with the practice of preconceptional FA intake are shown in Table 4.

According to the univariate analysis mothers aged 25 years or more $(p<0.01)$, mothers with higher educational attainment $(p<0.01)$ and higher socio-economic status $(p<0.01)$ and primiparous mothers $(p<0.01)$ were more likely to have preconceptional FA supplementations. Multivariate regression analysis showed, the higher maternal age $(p<0.01)$ and higher educational level of the mother $(p<0.05)$ and lower parity $(p<0.01)$ as the factors associated with the preconceptional FA intake among participants in the study sample.

The mothers who had taken FA during their pre-pregnant period stated the reason for them to take FA. The reasons stated by the mothers are shown in Table 5.

Among the mothers who had taken preconceptional FA, only 11(5.0\%) mothers correctly stated the importance of preconceptional FA as prevention of BD associated with the nervous system of the fetus. Another $78(35.8 \%)$ mothers stated that FA is important for the development of the nervous system of the fetus. The rest 129(59.2\%) were not aware about the importance of preconceptional FA in reducing BD.

Results of the univariate analysis of the association of socio-demographic factors on the awareness on the importance of preconceptional FA intake is shown in the Table 6. The mothers who stated that FA prevents BD and the mothers who stated that FA is important for the development of nervous system were taken collectively as the group aware on the importance of preconceptional FA. 
Table 4 Univariate and multivariate analysis of the effect of socio-demographic factors on preconceptional FA intake $(n=350)$

\begin{tabular}{|c|c|c|c|c|c|c|}
\hline \multirow[t]{2}{*}{ Characteristic } & \multicolumn{3}{|c|}{ Univariate analysis } & \multicolumn{3}{|c|}{ Multivariate analysis } \\
\hline & $\overline{O R^{b}}$ & $95 \% \mathrm{Cl}$ & $\overline{p \text { value }}$ & $\overline{O R^{b}}$ & $95 \% \mathrm{Cl}$ & $p$ value \\
\hline \multicolumn{7}{|l|}{ Age (years) } \\
\hline$\leq 24$ & 2.0 & $1.2-3.4$ & 0.007 & 2.1 & $1.2-3.7$ & 0.009 \\
\hline \multicolumn{7}{|l|}{$25-34^{\mathrm{a}}$} \\
\hline$\geq 35$ & 1.0 & $0.5-2.0$ & 0.957 & 0.8 & $0.4-1.5$ & 0.437 \\
\hline \multicolumn{7}{|c|}{ Monthly income (Sri Lankan Rupees) } \\
\hline$\leq 24,000$ & 3.4 & $1.7-6.7$ & 0.000 & 2.0 & $0.9-4.2$ & 0.072 \\
\hline $25-49,000$ & 2.4 & $1.2-4.6$ & 0.009 & 1.9 & $1.0-3.8$ & 0.049 \\
\hline \multicolumn{7}{|l|}{$\geq 50000^{a}$} \\
\hline \multicolumn{7}{|c|}{ Educational level of the mother } \\
\hline Up to secondary school & 2.6 & $1.6-4.4$ & 0.000 & 2.0 & $1.1-3.6$ & 0.019 \\
\hline \multicolumn{7}{|l|}{ Above secondary school ${ }^{a}$} \\
\hline \multicolumn{7}{|l|}{ Parity } \\
\hline \multicolumn{7}{|l|}{ Primiparous $^{\mathrm{a}}$} \\
\hline Multiparous & 2.0 & $1.3-3.2$ & 0.002 & 2.4 & $1.4-3.9$ & 0.001 \\
\hline
\end{tabular}

The awareness on the importance of preconceptional FA intake was not associated with any of the socio-demographics we analyzed. However, the mothers who have learnt or heard about BD demonstrated a better knowledge on the importance on preconceptional FA compared to those who had not heard about BD.

\section{Discussion}

The knowledge on BD among the antenatal mothers in Galle, Sri Lanka was found to be moderate in all the components namely; knowledge on $\mathrm{BD}$, knowledge on associated factors and knowledge on prevention and management. The overall knowledge on BD was $56.4 \%$. This stresses the urgent need for Sri Lanka to pay more attention towards public awareness on $\mathrm{BD}$, associated factors, prevention and management in order to reduce $\mathrm{BD}$ in the country in an era where BD cause a significant morbidity and mortality.

The mothers with higher educational attainment, mothers who were from wealthier families and mothers who had sought more antenatal care or had a higher

Table 5 The reasons for mothers to take pre-conceptional folic acid $(n=218)$

\begin{tabular}{lll}
\hline Reasons & $\mathrm{n}$ & $\%$ \\
\hline $\begin{array}{l}\text { To prevent the defects associated with the } \\
\text { nervous system of the fetus/ baby }\end{array}$ & 11 & 5.0 \\
$\begin{array}{l}\text { For the development of the nervous system } \\
\text { of the fetus/ baby }\end{array}$ & 78 & 35.8 \\
Taken but do not know the reason & 31 & 14.2 \\
Non-specific/ incorrect or invalid reason & 98 & 45.0 \\
\hline
\end{tabular}

number of clinic visits reported a better knowledge in all the components compared to the others. However, age, parity and having a child with BD did not show any association with the overall knowledge on BD. A study conducted in Ghana found that age, educational level, parity and number of clinic visits did not have a significant relationship with the knowledge on BD [3]. Studies done in Nigeria and Iran found a positive relationship between the knowledge on $\mathrm{BD}$ and the level of education which is consistent with the results of the present study [10-12]. A study done in Nigeria found a positive association between $\mathrm{BD}$ knowledge and age, social class, religion practiced and the location of the antenatal clinic center [12]. They stated that mothers who had received care from a tertiary hospital have had a better knowledge on $\mathrm{BD}$ compared to mothers who had received care from a local hospital [12]. The present study also was carried out at a community health area close to a medical faculty and two tertiary care hospitals. Therefore, the knowledge regarding $\mathrm{BD}$ could be higher among mothers who participated in the present study.

Our results indicate that mothers who had made more antenatal visits to health care workers or clinics have a higher overall knowledge on $\mathrm{BD}$. Therefore, the primary health care workers of Sri Lanka should ensure the attendance of the antenatal mothers at least for the minimum number of clinics scheduled for the mothers. Special attention should be paid for the mothers with low educational and low socio-economic status. However, the number of antenatal visits depends on the period of gestation of the mothers. In the current practice of Sri Lanka, the antenatal mothers should make a 
Table 6 Univariate analysis of the effect of socio-demographic factors on the correct knowledge on the importance of preconceptional FA $(n=218)$

\begin{tabular}{|c|c|c|c|}
\hline Characteristic & $\mathrm{OR}^{\mathrm{b}}(\%)$ & $95 \% \mathrm{Cl}$ & $P$ value \\
\hline \multicolumn{4}{|l|}{ Age (Years) } \\
\hline \multicolumn{4}{|l|}{$25-34^{\mathrm{a}}$} \\
\hline$\leq 24$ & 0.9 & $0.4-1.7$ & 0.688 \\
\hline$\geq 35$ & 1.1 & $0.5-2.4$ & 0.861 \\
\hline \multicolumn{4}{|l|}{ Monthly income (Rupees) } \\
\hline$\leq 24,000$ & 0.9 & $0.4-1.9$ & 0.825 \\
\hline $25-49,000$ & 1.0 & $0.6-1.9$ & 0.985 \\
\hline \multicolumn{4}{|l|}{$\geq 50000^{*}$} \\
\hline \multicolumn{4}{|c|}{ Educational level of the mother } \\
\hline Up to secondary school & 0.9 & $0.4-2.0$ & 0.839 \\
\hline \multicolumn{4}{|l|}{ Above secondary school ${ }^{a}$} \\
\hline \multicolumn{4}{|l|}{ Parity } \\
\hline Primiparous & 1.4 & $0.9-2.5$ & 0.177 \\
\hline \multicolumn{4}{|l|}{ Multiparous $^{\mathrm{a}}$} \\
\hline \multicolumn{4}{|l|}{ Number of clinic visits } \\
\hline Up to 5 & 0.7 & $0.2-2.5$ & 0.628 \\
\hline $6-15$ & 0.3 & $0.1-1.0$ & 0.046 \\
\hline \multicolumn{4}{|l|}{$\geq 16^{a}$} \\
\hline \multicolumn{4}{|l|}{ Heard about BD } \\
\hline Yes & 0.4 & $0.2-0.9$ & 0.018 \\
\hline $\mathrm{No}^{\mathrm{a}}$ & & & \\
\hline
\end{tabular}

${ }^{\mathrm{a}}$ Reference category, ${ }^{\mathrm{b} O R}$ - Odds Ratio

minimum of nine field antenatal clinic visits and should receive three domiciliary visits in an uncomplicated pregnancy [13]. The number of field visits and consultations by the consultant obstetrician depends on the risk assessment of the mother [13]. It also varies according to the health seeking behavior of the mother. In contrast to the results of the present study, several studies have shown that there is no association between the number of antenatal visits and the knowledge on $\mathrm{BD}[3,11]$. This difference in knowledge could be due to the routine nature of the antenatal clinics, the format of the antenatal sessions and the topics discussed at the antenatal clinics in the study setting. This might have been influenced by the health seeking behavior of mothers in the study area. Therefore, the antenatal care services and the health seeking behavior of the mothers in Galle, Sri Lanka seem to be effective in increasing knowledge on BD. Since the mothers should possess knowledge on BD ideally before they become pregnant, health education about $\mathrm{BD}$ should be commenced during the preconceptional period rather than during the antenatal period.

In this study group 62.3\% $(n=218)$ mothers have taken pre-conceptional FA. It is satisfactory compared to a study done in Kandy, Sri Lanka where preconceptional
FA consumption among two groups; mothers with and without children with neural tube defects (NTD) was $0 \%$ and $13 \%$ respectively [14]. Many researchers have found a low preconceptional FA intake among mothers in many communities [15-17]. Some studies stressed on the low preconceptional FA intake even though many participants have heard about FA $[15,17-$ 19]. A study done in Taiwan, found that preconceptional FA intake was only $15.6 \%$, though nearly $90 \%$ of the sample of women was aware of folic acid [18]. It states about a possibility of these mothers getting aware of FA after they become pregnant, since the study was conducted among the antenatal mothers. A study done in Pakistan found that very few had received FA supplementation during pre-pregnancy and pregnancy period. According to them, only $51.25 \%$ had received FA even during pregnancy [20].

We found that the preconceptional FA intake is positively associated with higher maternal age, higher educational level and lower parity of the mother. Nilsen and collegues also found a better preconceptional FA intake associated with higher maternal age, higher education, and lower parity which is consistent with our study [16]. Several other studies also found that preconceptional FA intake is higher among mothers with higher education [17, 19-21]. Therefore, Sri Lanka should pay further attention on education of the adolescent girls in the country. Within the education systems knowledge on reproductive health should be disseminated including the knowledge on $\mathrm{BD}$ and prevention. Through that, positive health behaviors like preconceptional FA intake by eligible females can be expected while increasing the awareness on $\mathrm{BD}$, associated factors and prevention. Then Sri Lanka can achieve a reduction of $\mathrm{BD}$, along with the associated morbidity and mortality.

This study revealed that preconceptional FA intake is higher among primiparous mothers $(p<0.01)$. In Sri Lanka, a preconception care package was introduced in 2012 as a part of the maternal care package for the Sri Lankan mothers, particularly targeted for newly married couples [9] and may be an explanation for the higher proportion of primiparous mothers taking preconceptional FA identified in our study results. Therefore, this finding of our study stresses the necessity of care before the subsequent pregnancies.

Among the mothers who have taken preconceptional FA only $5.04 \%$ stated that it prevents the BD of the nervous system of the baby and another $35.8 \%$ stated that it is needed for the development of the nervous system of the baby. About $14.2 \%(n=31)$ were not aware of the importance of preconceptional FA and the rest $44.9 \%(n=98)$ stated nonspecific or incorrect reasons on the importance of preconceptional FA. This finding stresses the fact that even the women who 
took FA preconceptionally, have inadequate knowledge about the importance of FA. If the mothers were aware on the NTD prevention associated with FA, the preconception FA intake would more likely to be much higher. Therefore, when prescribing FA to the eligible females it is important to highlight the importance of preconceptional intake of FA. Dissanayake and collegues concluded on a grossly inadequate knowledge on FA in Sri Lanka, even among the mothers having children with NTD [14]. Many studies have revealed inadequate awareness about the importance of FA and stressed on the importance of public health strategies to increase awareness on FA $[14,15,19-23]$. However, countries like Israel and Canada have shown a higher prevalence of folate awareness [19]. It would be better to look for the methods they have used to achieve these targets when planning public health strategies to increase awareness on FA among Sri Lankan mothers.

According to the results of the present study no association between the socio-demographic factors and the knowledge on the importance of preconceptional FA was elicited. Our finding is consistent with the results derived by Nosrat and collegues [15]. However, many studies showed associations between the awareness on FA and socio-demographics. An Ethiopian study revealed that women with better family income were more aware of the importance of FA [21]. Many other studies revealed a better awareness on FA among females with higher educational attainment $[17,19,21,22]$. This might be an evidence for the fact that there is a lack in the education curriculums of Sri Lanka with regard to certain health aspects like BD prevention.

Prevention of NTD is highly associated with the "preconceptional consumption" of FA since the neural tube develops by the 28th day of gestation, a time period where the mother herself is not aware about the pregnancy $[17,18,24]$. Two major methods, namely; creating awareness on FA and supplementation of FA among the females in the child bearing age have been identified as main preventive strategies against NTD [18]. In the supplementation of folic acid for females in childbearing age, fortification plays a major role and the other method of supplementation is tablets containing FA [2, 25]. Jou and collegues cited that fortification has shown a 31 and $16 \%$ reduction in the prevalence of spina bifida and anencephaly respectively in the United States once US has fortified the food with FA [18]. Many other countries like Canada, Costa Rica, Chile and South Africa also have shown a significant reduction of NTD after food fortification with FA [2]. In countries like Sri Lanka, where such a policy is not being practiced yet [2], making the public aware on the importance of FA through health education would be the best method to reduce the NTD, which showed a prevalence of 1.4 per 1000 live births [14]. With a better awareness on the importance of FA, preconception FA intake would be increased in the country. When making plans to make the eligible females aware of the importance of FA, it is important to make them aware from their adolescence while they are in the schools to have a better coverage.

Many researchers have investigated for the methods of acquiring knowledge about $\mathrm{BD}$ and FA among the communities. Many revealed mass media and health care workers as the main sources of information on BD and FA $[12,17,22]$. When considering the methods of acquiring knowledge about BD in the present study, PHM, printed and electronic media were the leading sources of knowledge to the mothers. Dissanayake and collegues also stated family health worker as the main source of information on FA to the mothers followed by media [14]. This may be due to the PHMs' role as the grass root level health care workers in the delivery of field maternal and child care services in Sri Lanka. It might be further strengthened by the close relationship between the Sri Lankan mothers and the PHMs. This finding gives a positive feedback to initiate the $\mathrm{BD}$ prevention programmes through the PHMs, a well-established, strong platform with proven results in uplifting the maternal and child health in the country. Wide availability of electronic media like television and radio also has played a major role in delivering health messages to the community of Sri Lanka.

However, the knowledge on $\mathrm{BD}$, gained through a medical officer is not satisfactory in this target group although in some studies medical practitioners were found to be the major source of information $[18,19]$. Therefore, public awareness through medical practitioners should be given more attention in Sri Lanka in order to prevent BD. A study conducted in Poland found internet as the major source of information for the participants of the study [26]. This would be useful for Sri Lanka as well because the knowledge can be disseminated through internet and social media. This can be applied especially to the teenagers; the next generation of parents, among whom social media and internet usage is highly prevalent [27]. Some studies have tested and proved the effectiveness of various health education methods and materials with regard to prevention of certain causes of BD [28-31]. Many researchers have targeted on the awareness and intake of FA [28-30]. The "Promotora de Salud model" which relied on interpersonal connections of the community health workers, has shown an increased awareness and practice of FA among the participants in several studies [28, 29]. Sri Lanka also can practice this method through PHMs. Effectiveness of health education through village clinics, written materials and text messages was shown in a study conducted 
among rural Chinese women [30]. A study done in Poland to assess the impact of health education on knowledge and prevention behaviour of congenital toxoplasmosis has stressed the necessity of modern promotional technologies apart from the traditional written education materials [31].

For Sri Lanka, prevention of BD is a key priority in child health due to the fact that $\mathrm{BD}$ associated mortality is a leading cause for infant and 1-5 year child mortality. If the public is much aware about the gravity of $\mathrm{BD}$, they would be interested in learning about BD and their prevention. According to a Nigerian study, $86.5 \%$ of the respondents believed that more public education can reduce the occurrence of $\mathrm{BD}$ [4]. Therefore, public awareness through health education seems to be one of the major methods and a key priority in the prevention of BD in Sri Lanka. When planning the health education programs on BD in Sri Lanka, methods like education through PHMs and medical officers, distribution of pamphlets among the eligible females, giving messages through the electronic and social media and text (SMS) and video (MMS) messages need to be considered and implemented without any delays.

We gathered data from a sample of 350 antenatal mothers which is relatively a large sample. Data was collected from six field antenatal clinic centers. Data collection was performed by a single investigator which would have increased the consistency in data collection approach. These were the strengths of the study.

There were few limitations to the study. This study was confined to one health unit area. We were not able to recruit few (less than $5 \%$ ) participants from ethnic groups other than Sinhalese due to their inability to read and write Sinhala language. Also due to the self-administered nature of the questionnaire mothers might have understood the responses with minor variations.

\section{Conclusions}

The knowledge about BD, associated factors, prevention and management among antenatal mothers was found be moderate in this study population. The knowledge on the importance of preconceptional FA is found to be inadequate. Therefore, effective health education programs like education through PHMs and medical officers, distribution of pamphlets among the eligible females, giving messages through electronic and social media and mobile phones need to be developed and implemented. Printed and electronic media and the PHMs seem to be the effective sources that can be used to disseminate knowledge on $\mathrm{BD}$. Medical practitioners should pay more attention towards health education of their clients on $\mathrm{BD}$ and prevention of BD. They should target especially on cost effective interventions like preconception
FA supplementation, nutrition education and infection prevention. It is needed to emphasize the importance of FA when prescribing FA to the eligible females in order to have a better compliance. When delivering preconception care services, care before the subsequent pregnancies also should be considered.

\section{Additional file}

\begin{abstract}
Additional file 1: Questionnaire to assess the knowledge of the antenatal mothers on birth defects, associated factors, prevention and management. This is a self-administered questionnaire used to collect data from the antenatal mothers. In the development of the questionnaire for the present study, the questionnaire developed by Bello et al., (2013) was used as a reference [3]. Additional questions were added to address the aims of the study. The questionnaire consisted of two parts; part A and part B. Part A of the questionnaire was used to gather socio-demographic data including age, ethnicity, highest educational qualification, monthly income, parity, previous children with birth defects, and the number of clinics attended. Data was obtained on prior awareness on birth defects and the sources of such information. An added question was included to inquire on the preconceptional FA intake. If FA was taken preconceptionally, the reason for them to take preconceptional FA supplementation was inquired. Part $B$ of the questionnaire consisted of three sections; knowledge on $\mathrm{BD}$, knowledge on associated factors of $\mathrm{BD}$ and knowledge on prevention and management of BD. Respectively, 10, 21 and 7 statements were included in each section. In all 3 sections mothers were asked to mark their responses stating whether the given statement is true, false or do not know. (DOCX $22 \mathrm{~kb}$ )
\end{abstract}

\section{Abbreviations}

BD: Birth defects; FA: Folic acid; NTD: Neural tube defects; PHM: Public Health Midwife

\section{Acknowledgements}

We are grateful to the antenatal mothers who participated in the study, and to the Regional Director of Health Services in Galle district and the Medical Officer of Health at Bope-Poddala for granting permission to carry out the study at the field antenatal clinic set-up.

This study has been conducted as the first phase of a larger study which was carried out to describe the Associate factors, outcomes and prevention of birth defects among infants in Southern Sri Lanka.

\section{Funding}

This study was funded by the University Block Grants for Strengthening Research 2016 (Reference No: 2016/RU/PG-R/16/11) of the University of Ruhuna, Sri Lanka.

\section{Availability of data and materials}

The datasets used and/or analyzed during the current study are available from the corresponding author on reasonable request.

\section{Authors' contributions}

JDS, worked as the principal investigator of the research study and did the data collection, analysis and writing. SA, KJ and BP are the supervisors of JDS and actively participated in writing the manuscript. BP was involved in data analysis. All authors read and approved the final manuscript.

\section{Ethics approval and consent to participate}

To conduct the study Ethical approval was obtained from the Ethical Review Committee of the Faculty of Medicine, University of Ruhuna, Galle, Sri Lanka (Reference No: 17/11/14. 3.4). Permission was obtained from the Regional Director of Health Services of Galle district and from the Medical Officer of Health of the Bope-Poddala Medical Officer of Health Unit area of Galle district to recruit mothers for the study. Informed written consent was obtained from all the participants after an initial information session. 


\section{Consent for publication}

Not applicable.

\section{Competing interests}

The authors declare that they have no competing interests.

\section{Publisher's Note}

Springer Nature remains neutral with regard to jurisdictional claims in published maps and institutional affiliations.

\section{Author details}

'Department of Community Medicine, Faculty of Medicine, University of Ruhuna, Galle, Sri Lanka. ${ }^{2}$ Department of Paediatrics, Faculty of Medicine, University of Ruhuna, Galle, Sri Lanka. ${ }^{3}$ Family Health Bureau, Ministry of Health, Colombo, Sri Lanka.

\section{Received: 23 October 2018 Accepted: 26 December 2018}

Published online: 17 January 2019

\section{References}

1. Christianson A, Howson CP, Modell B. March of Dimes Global report on Birth Defects: The hidden toll of dying and disabled children. New York (NY): March of Dimes Birth Defects Foundation; 2006.76p.

2. World Health Organization. Prevention and control of Birth Defects in South-East Asia Region: Strategic Framework 2013-2017. New Delhi: World Health Organization, Regional office for South-East Asia; 2013. p. 64.

3. Bello Al, Acquah AA, Quartey NA, Hughton A. Knowledge of pregnant women about birth defects. BMC Pregnancy Childbirth. 2013;13:45.

4. Peter Al, Ekong MB, Ekanem TB, Umoh IU, Edagha IA, Davies KG, et al. Attitude and knowledge of pregnant women attending antenatal clinic at St. Luke's hospital, Anua in Uyo, Nigeria towards congenital anomalies. Ibom Med J. 2013;6(2):34-40.

5. World Health Organization. Congenital Anomalies [Internet]. Geneva: World Health Organization; 2016. Available from: https://www.who.int/news-room/ fact-sheets/detail/congenital-anomalies. Accessed 31 Oct 2017.

6. Fernando S, Bandara T, Sathanantharajah R, Withanaarachchi K. Pattern of clinically recognizable congenital malformations in babies born in a tertiary referral Centre in Sri Lanka. Ceylon Med J. 2014;59(4):132-5.

7. Family Health Bureau. Annual Report 2013. Colombo (LK): Family Health Bureau, Ministry of Health; 2014.

8. Family Health Bureau. Annual Report 2015. Colombo (LK): Family Health Bureau, Ministry of Health; 2016.

9. Family Health Bureau. Annual Report 2016. Colombo (LK): Family Health Bureau, Ministry of Health; 2018.

10. Owotade FJ, Ogundipe OK, Ugboko VI, Okoje VN, Olasoji HO, Makinde ON, et al. Awareness, knowledge and attitude on cleft lip and palate among antenatal clinic attendees of tertiary hospitals in Nigeria. Niger J Clin Pract. 2014;17(1):6-9.

11. Masoumeh P, Vahid K, Hamid AM, Khosheh K, Samira K. Knowledge of pregnant women about congenital anomalies: a cross-sectional study in north of Iran. Indian J Health Sci. 2015;8(1):41-7.

12. Lawal TA, Yusuf $O B$, Fatiregun AA. Knowledge of birth defects among nursing mothers in a developing country. Afr Health Sci. 2015;15(1):180-7

13. Family Health Bureau. Maternal Care Package: A quide to Field Healthcare Workers. Colombo (LK): Family Health Bureau, Ministry of Health; 2011. 216 p.

14. Dissanayake NN, Wickramasinghe SC, Bandara DW. Study on neural tube defects of neonates and folic acid awareness at a teaching Hospital in Sri Lanka. Sri Lanka J Child Health. 2010:39:11-6.

15. Nosrat SB, Sedehi M, Golalipour MJ. Knowledge and practice of urban Iranian pregnant women towards folic acid intake for neural tube defect prevention. J Pak Med Assoc. 2012;62(8):785-9.

16. Nilsen RM, Leoncini E, Gastaldi P, Allegri V, Agostino A, Faravelli F, et al. Prevalence and determinants of preconceptional folic acid use: an Italian multicenter survey. Ital J Pediatr. 2016;42(65).

17. Kim J, Yon M, Kim C, Lee Y, Moon G, Hong J, et al. Preconceptional use of folic acid and knowledge about folic acid among low-income pregnant women in Korea. Nutr Res Pract. 2017:11(3):240-6.

18. Jou HJ, Hsu IP, Liu CY, Chung SH, Chen SM, Gau ML. Awareness and use of folic acid among pregnant women in Taipei. Taiwan J Obstet Gynecol. 2010;49(3):306-10.
19. Bener A, Mohammed GA, Al-Bast AE, Al-Marri S. Maternal knowledge, attitude and practice on folic acid intake among Arabian Qatari women. Reprod Toxicol. 2005;21:21-5

20. Hisam A, Rahman M, Mashhadi SF. Knowledge, attitude and practice regarding folic acid deficiency; a hidden hunger. Pak J Med Sci. 2014;30(3): 583-8.

21. Goshu YA, Liyeh TM, Ayele AS, Zeleke LB, Kassie YT. Women's awareness and associated factors on preconception folic acid supplementation in Adet, northwestern Ethiopia, 2016: implication of reproductive health. J Nutr Metabol. 2018;2018:1-7.

22. Unusan N. Assessment of Turkish women's knowledge concerning folic acid and prevention of birth defects. Public Health Nutr. 2004;7(7):851-4.

23. Ahmad B, Anam H, Khalid N, Mohsen R, Zaal L, Jadidy E, et al. Perceptions of women of reproductive age about vitamin and folic acid supplements during pregnancy, Taibah University, Almadinah Almunawwarah, Kingdom of Saudi Arabia. J Taibah Univ Med Sci. 2013;8(3):199-204.

24. Peake JN, Copp AJ, Shawe J. Knowledge and Periconceptional use of folic acid for the prevention of neural tube defects in ethnic communities in the United Kingdom: systematic review and meta-analysis. Birth Defect Res A Clin Mol Teratol. 2013:97:444-51.

25. Green-Raleigh K, Carter H, Mulinare J, Prue C, Petrini J. Trends in folic acid awareness and behaviour in the United States: the Gallup Organization for the March of Dimes Foundation surveys, 1995-2005. Matern Child Health J. 2006:10:5177-82

26. Jamrozik P, Przybyla A, Szelag E. The assessment of mothers' knowledge on the underlying causes and available prophylaxis of congenital defects in children. J Public Health Nurs Med Rescue. 2013;04:43-50.

27. Thuseethan S, Kuhanesan S. Influence of Facebook in Academic Performance of Sri Lankan University Students. Global Journal of Computer Science and Technology: E Network, web and security [Internet]. 2014;14(4) Available from: https://globaljournals.org/GJCST_Volume14/5-Influence-ofFacebook-in-Academic.pdf. Accessed 19 Mar 2018.

28. de Rosset L, Mullenix A, Flores A, Mattia-Dewey D, Mai CT. Promotora de Salud: promoting folic acid use among Hispanic women. J Women's Health (Larchmt). 2014:23(6):525-31.

29. Flores AL, Isenburg J, Hillard CL, deRosset L, Colen L, Bush T, et al. Folic acid education for Hispanic women: the Promotora de Salud model. J Women's Health. 2017;26(2):186-94.

30. Lin Q, Yang L, Li F, Qin H, Li M, Chen J, et al. A village-based intervention: promoting folic acid use among rural Chinese women. Nutrients. 2017; 9:174.

31. Pawlowski ZS, Gromadecka-Sutkiewicz M, Skommer J, Paul M, Rokossowski $H$, Suchocka E, Schantz PM. Impact of health education on knowledge and prevention behavior for congenital toxoplasmosis: the experience in Poznan, Poland. Health Educ Res. 2001;16(4):493-502.

Ready to submit your research? Choose BMC and benefit from:

- fast, convenient online submission

- thorough peer review by experienced researchers in your field

- rapid publication on acceptance

- support for research data, including large and complex data types

- gold Open Access which fosters wider collaboration and increased citations

- maximum visibility for your research: over $100 \mathrm{M}$ website views per year

At $\mathrm{BMC}$, research is always in progress.

Learn more biomedcentral.com/submission 